EESTI NSV TEADUSTE AKADEEMIA TOIMETISED, 27. KOIDE KEEMIA. 1978, NR. 1

ИЗВЕСТИЯ АКАДЕМИИ НАУК ЭСТОНСКОИ ССР. ТОМ 27 ХИМИЯ. 1978, № 1

Хелле МАРТИНСОН

удК 001.89

\title{
АНАЛИЗ КАДРОВОГО ПОТЕНЦИАЛА ИНСТИТУТА ХИМИИ АН ЭССР С 1947 ПО 1975 г.
}

\section{Введение}

При оценке эффективности современной науки и поисках путей дальнейшего ее повышения важную роль играет анализ существующего потенциала науки и возможностей обеспечения ее в будущем. Научный потенциал представляет собой комплекс параметров: обеспеченность науки кадрами, научно-информационная и материально-техническая оснащенность и оптимальность организации данной научной системы. Лишь с учетом динамики указанных показателей за определенный период можно оценить научную продуктивность коллектива ученых и дать хотя бы приблизительную оценку научной и экономической эффективности его деятельности.

В самом широком смысле эффективность исследований количественно или качественно оценивается по отношению результатов научной работы, или полученного эффекта от их применения, к затратам (труда, материалов, установок) на выполнение этой работы. Однако фундаментальные исследования представляют собой потенциал, реализуемый по мере использования их результатов на практике, он имеет прогнозный, вероятностный характер. Эффективность фундаментальных работ может быть оценена лишь приблизительно по новизне результатов, по их ценности для общества, ширине применимости и реализуемости за определенный период времени.

Эффективность научных исследований в настоящее время оценивается на основе а) косвенных показателей - цитируемости, научного авторитета учреждения или отдельных ученых, потенциальной внедряемости результатов, премий и наград и т. д.; б) количественных показателей - числа авторских свидетельств и открытий, публикаций, квалификационного состава и численности научного коллектива, коэффициента использования аппаратуры и других показателей.

При анализе косвенных показателей трудно учесть специфику деятельности как учреждения в целом, так и отдельных его подразделений, а также оценить истинную научную значимость полученных результатов. Анализ же количественных показателей развития научного учреждения, т. е. научного потенциала (число сотрудников и публикаций, сумма затрат и т. д.), позволяет все же в рамках одного института или группы учреждений одного профиля выявить некоторые общие закономерности развития организаций в целом, а также отдельных научных направлений. Сравнение продуктивности коллективов ученых позволяет охарактеризовать их творческую активность и в какой-то мере предсказать общие 
тенденции развития тех или иных научных направлений на ближайший период.

В последнее время одним из наиболее объективных показателей распространения и значимости научных идей, содержащихся в работе или в совокупности работ определенного коллектива или направления, считается цитируемость их. Цитируемость работ показывает, что они послужили толчком для развития новых трудов, приведенные в них предложения и выводы использованы в науке.

В настоящей работе на основе статистических данных о динамике кадров проанализировано развитие одного научного коллектива - Института химии Академии наук ЭССР за 28 лет его существования.

\section{Организация и структура института}

Институт химии был создан в системе Академии наук Эстонской ССР в начале 1947 г. в тяжелых условиях первых послевоенных лет.

Первые годы существования института были посвящены решению организационных вопросов, укомплектованию кадрами и поиску актуаль-

ИЗMEHEHИЯ В СТРУKTYPE ИHCTИTYTA ХИMИИ AH ЗССР *

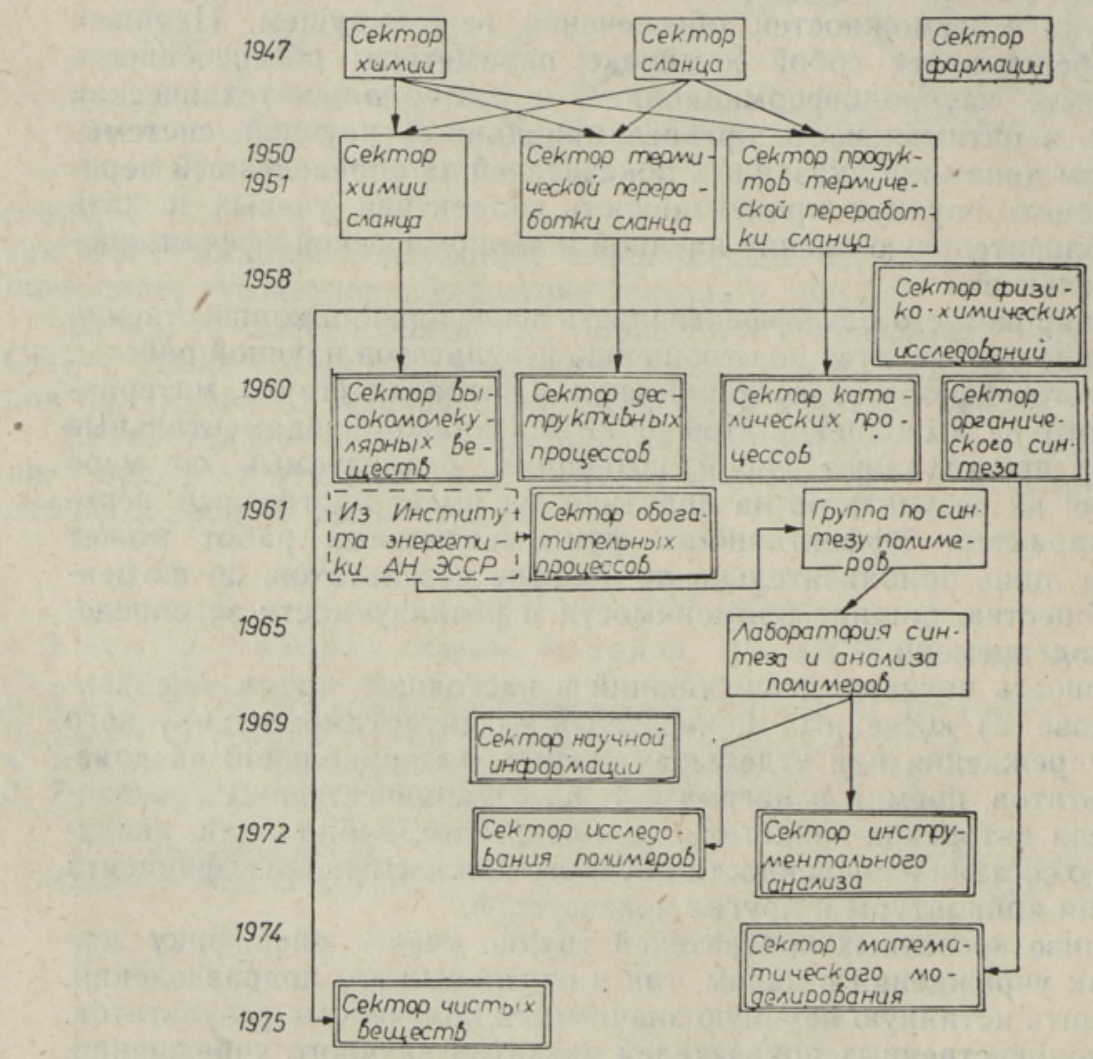

* В двойной рамке - секторы, существующие в настоящее время.

ных научных направлений - их можно рассматривать как период формирования учреждения. 50-е годы стали периодом нсследования проблем сланцевой химии и технологии. К концу $50-$ х годов уже вырисовывались 
новые научные направления - физико-органическая химия (применение методов хроматографии и спектрофотометрии для установления состава сложных смесей органических соединений), тонкий органический синтез (синтез душистых веществ и витаминов на базе диеновых углеводородов, синтез поверхностно-активных веществ, получение чистых органических реактивов) и изучение возможностей комплексного использования месторождений полезных ископаемых Эстонской ССР. К этим направлениям, определяющим в основном профиль института и в настоящее время, в 70-х годах прибавились биоорганическая химия (синтез липидов и гормонов, связывание ферментов на поверхности полимеров) и теоретические основы химической технологии.

Наряду с определением научных направлений имели место и организационные преобразования. Изменения в структуре института иллюстрирует схема.

\section{АНАЛИЗ ОБЕСПЕЧЕННОСТИ ИНСТИТУТА ХИМИИ АН ЭССР НАУЧНЫМИ КАДРАМИ}

\section{Численность научного персонала}

Рост количества ученых и инженерно-технического персонала является одним из количественных показателей, наиболее четко характеризующих темпы развития науки в XX веке. Судя по этому показателю,

Таблица 1

Количество научных работников в СССР, ЭССР и АН ЭССР и динамика

его прироста в $1950-1974$ гг.

\begin{tabular}{|c|c|c|c|c|c|c|c|}
\hline Год & $\begin{array}{c}\text { Научных } \\
\text { работников } \\
\text { в СССР }\end{array}$ & Прирост, & $\begin{array}{c}\text { Научных } \\
\text { работников } \\
\text { в ЭССР }\end{array}$ & $\underset{\%}{\text { Прирост, }}$ & $\mid \begin{array}{c}\% \text { от тем- } \\
\text { пов при- } \\
\text { роста в } \\
\text { СССР }\end{array}$ & $\begin{array}{c}\text { Научных } \\
\text { работни- } \\
\text { ков в АН } \\
\text { ЭССР }\end{array}$ & Прирост, \\
\hline 1950 & 162508 & 100,0 & 1221 & 100,0 & 100,0 & 274 & 100,0 \\
\hline 1955 & 223936 & 137,8 & 1618 & 132,5 & 96,2 & 367 & 133,9 \\
\hline 1960 & 354158 & 218,0 & 2227 & 182,4 & 83,7 & 481 & 175,5 \\
\hline 1965 & 664584 & 409,0 & 3473 & 284,4 & 69,5 & 561 & 204,7 \\
\hline 1970 & 927700 & 570,9 & 4707 & 385,5 & 67,5 & 768 & 280,3 \\
\hline 1974 & 1169700 & 719,8 & 5748 & 470,8 & 65,4 & 873 & 318,6 \\
\hline
\end{tabular}

Таблица 2

Прирост количества сотрудников, научных сотрудников, докторов и кандидатов наук, числа научных публикаций и бюджета Института химии $(1948-1950 \mathrm{rr} .=100)$

\begin{tabular}{|c|c|c|c|c|c|}
\hline & \multicolumn{5}{|c|}{ Годы } \\
\hline & 1955 & 1960 & 1965 & 1970 & 1975 \\
\hline $\begin{array}{l}\text { Прирост общего количества сотруд- } \\
\text { ников }\end{array}$ & 131,2 & 277,0 & 516,1 & 658,9 & 830,9 \\
\hline Прирост научных сотрудников & 157,1 & 300,0 & 514,3 & 657,1 & 792,9 \\
\hline $\begin{array}{l}\text { То же самое в целом по Академии } \\
\text { наук ЭССР }(1947-1950 \text { гг. }=100)\end{array}$ & 126,1 & 165,3 & 192,8 & 263,9 & 326,1 \\
\hline $\begin{array}{l}\text { Прирост числа докторов и кандида- } \\
\text { тов наук }\end{array}$ & 128,6 & 214,3 & 485,7 & 700,0 & 885,7 \\
\hline Прирост научных публикаций & 132,0 & 434,0 & 1018,9 & 1509,4 & 2566,0 \\
\hline$=100)$ & 87,5 & 198,1 & 395,9 & 697,2 & 1121,2 \\
\hline
\end{tabular}




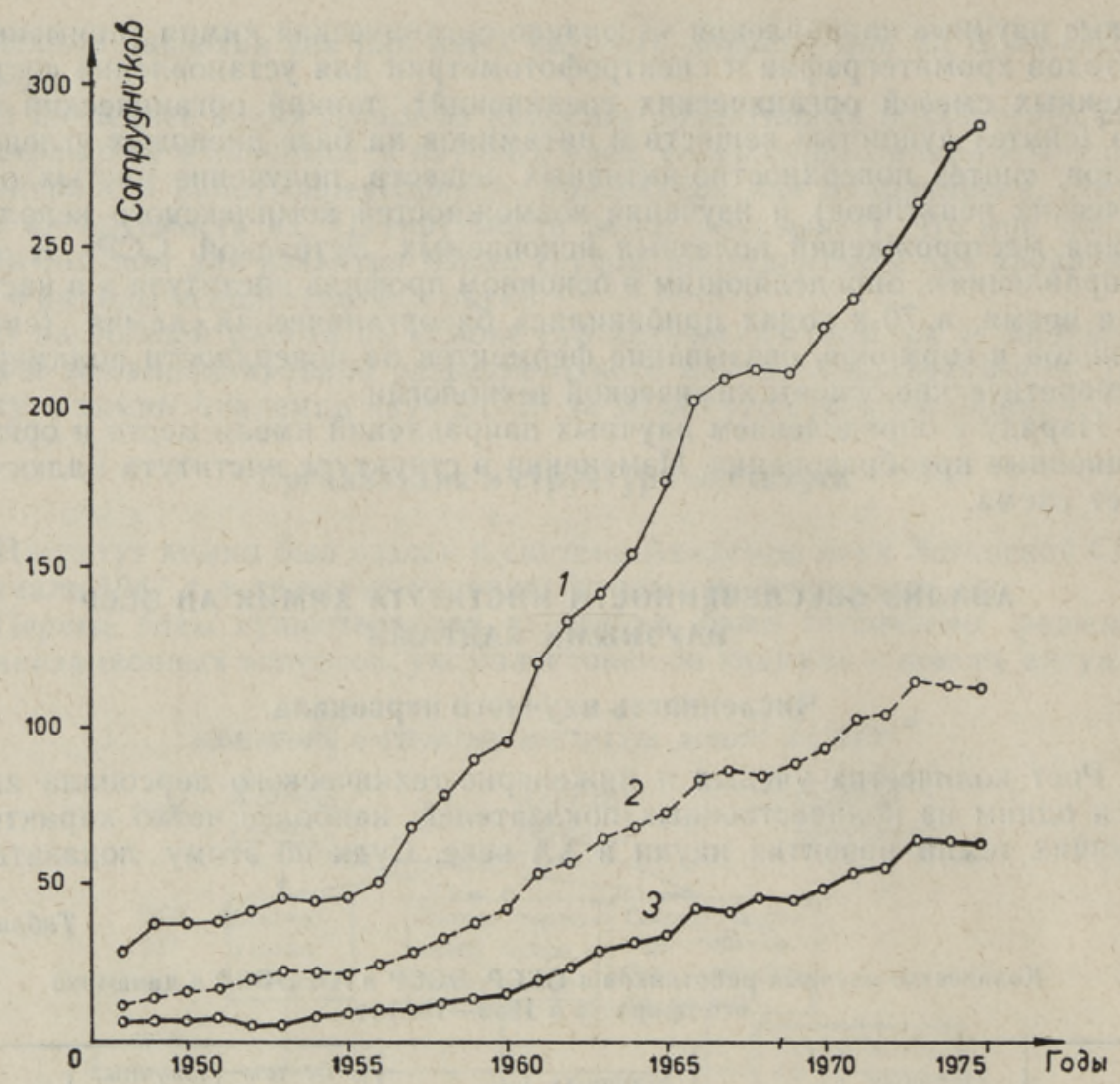

Рис. 1. Рост численности сотрудников Института химии. 1 - число всех сотрудников, 2 - число научных сотрудников, 3 - число сотрудников с учеными степенями.

наука как сфера занятости людей в СССР развивалась в три раза быстрее, чем другие области. Число научных работников в СССР увеличилось с 1950 по 1974 г. в 7,2 раза (см. табл. 1; [1,5]). В Эстонской ССР число ученых возрастало так же стремительно. Однако с 1958 г. прирост числа научных работников в ЭССР по сравнению с приростом числа научных работников в СССР резко замедлился, а прирост числа научных сотрудников в Академии наук ЭССР оказался даже ниже, чем в целом по республике. Среди других республик Эстонская ССР по этому показателю постоянно находится на предпоследнем или последнем месте.

Как видно по рис. 1, где изображена динамика прироста численности сотрудников Института химии АН ЭССР за 1947-1975 гг. [ $\left.{ }^{2}\right]$, до 19561957 гг. число сотрудников увеличивалось относительно медленно, а затем более стремительно. Кривые роста числа научных работников и сотрудников с учеными степенями на рис. 1 имеют менее крутые подъемы (более крутыми они стали после 1960 г.). Если же сопоставить скорость прироста среднегодовой численности научных работников и сотрудников с учеными степенями Института химии со скоростью роста численности научных сотрудников в целом Академии наук ЭССР, то выясняется, что в последнем она гораздо медленнее и что прирост числа научных сотрудников здесь значительно отстает от прироста числа сотрудников в Институте химии (см. рис. 2). Так, прирост количества сотрудников в АН ЭССР 


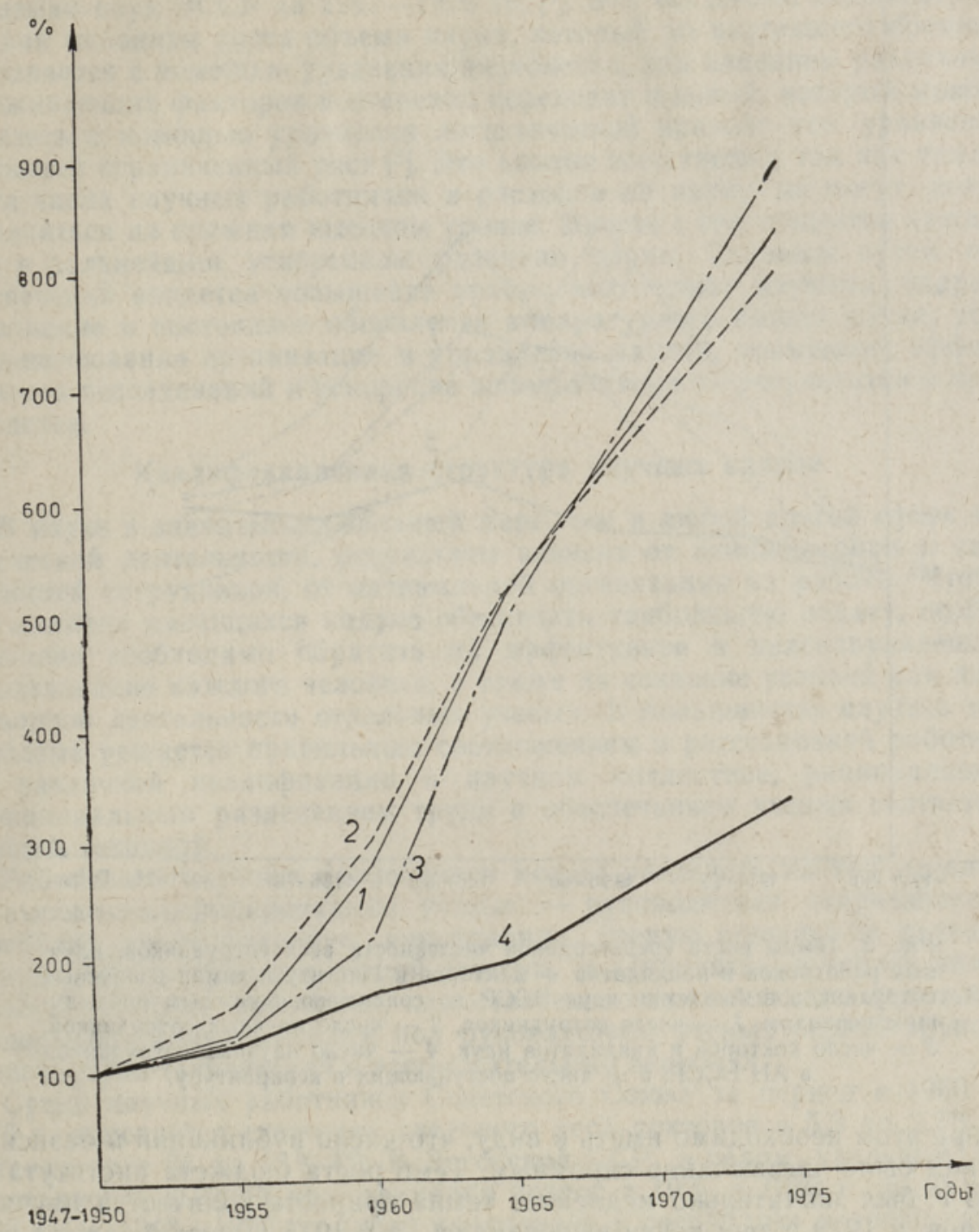

Рис. 2. Темпы прироста среднегодовой численности сотрудников Института химии. 1 - всех сотрудников, 2 - научных сотрудников, 3 - сотрудников с учеными степенями, 4 - научных сотрудников в АН ЭССР.

в 1975 г. по сравнению с периодом 1947-1950 был более чем в 2 раза ниже этого показателя для института.

Темп роста количества сотрудников и научных сотрудников Института химии до 1965 г. превышал темп роста сотрудников с учеными степенями, а позже рост числа сотрудников с учеными степенями стал опережать рост числа сотрудников без ученых степеней (табл. 2).

K 1975 г. численность сотрудников с учеными степенями возросла почти в 8,9 раза, в то время как общая численность сотрудников - в 8,3 раза, а численность научных сотрудников - в 7,9 раза.

Количество наименований научных публикаций росло значительно быстрее - за рассматриваемый пернод увеличилось примерно в 25 раз, 


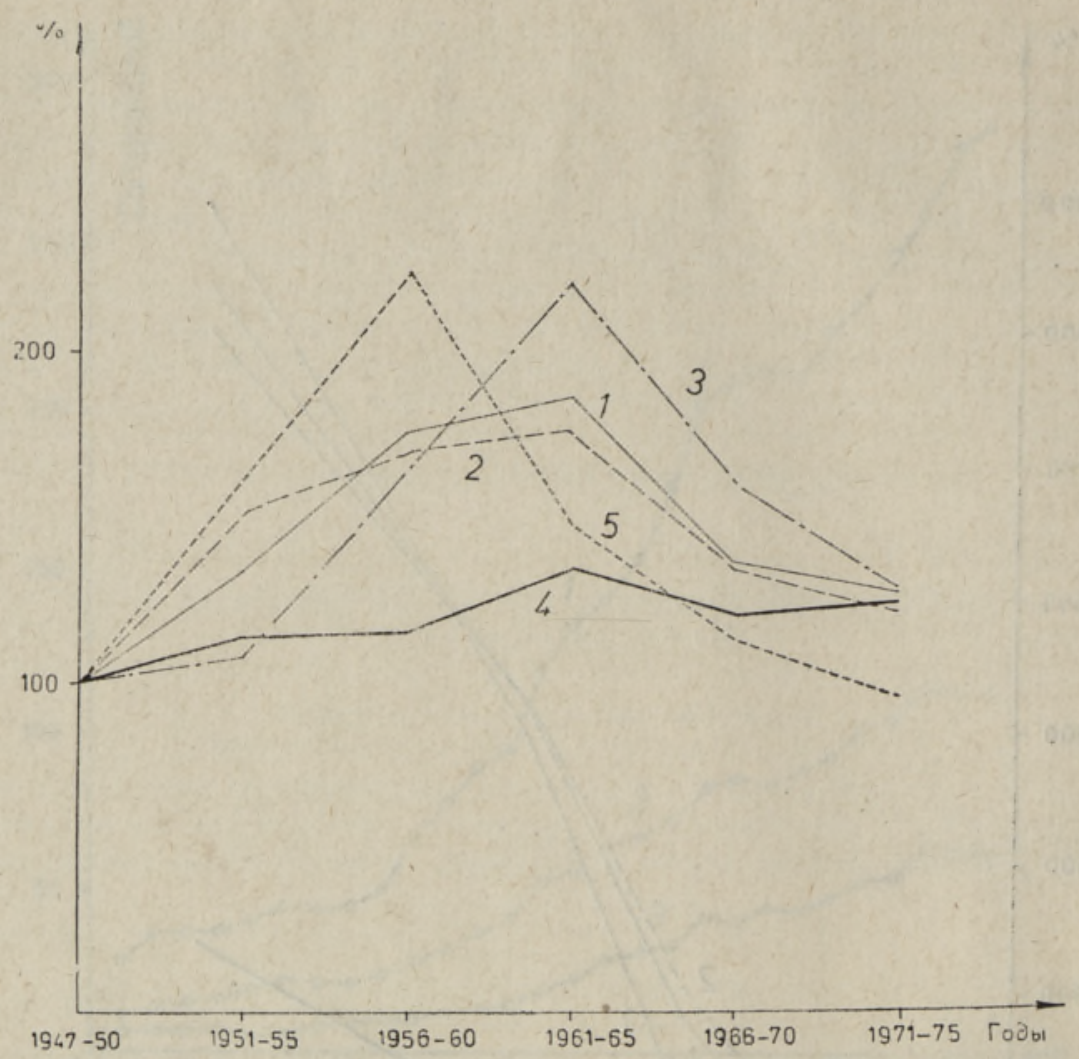

Рис. 3. Темпы роста среднегодовой численности всех сотрудников, научных работников и кандидатов + докторов в Институте химии и научных сотрудников в Академии наук ЭССР по сравнению с каждым предыдущим периодом. 1 - число сотрудников, 2 - число научных сотрудников, 3 - число докторов и кандидатов наук, 4 - число научных сотрудников в АН ЭССР, 5 - число поступающих в аспирантуру.

но при этом необходимо иметь в виду, что число публикаций в базисный период было чрезвычайно скромным. Темп роста бюджета института до 1965 г. был значительно медленнее темпа прироста количества научных кадров, к 1970 г. они почти выровнялись, а к 1975 г. рост бюджета опережал рост числа сотрудников (за рассматриваемый период увеличился в 11 раз).

Таким образом, эти данные свидетельствуют о стремительных темпах роста основных количественных показателей развития рассматриваемого научного коллектива.

Если же рост численности научных кадров института проанализировать с несколько иной точки зрения, т. е. сравнить прирост количества сотрудников в среднем в год (в процентах) с приростом за каждый предыдущий период (рис. 3), то вырисовывается совершенно иная картина. Получается, что общее количество сотрудников, научных работников, кандидатов и докторов наук, вместе взятых, а также число поступающих в аспирантуру и количество защищенных диссертаций (табл. 6) росли по сравнению с каждым предыдущим периодом до 1965 г. (число поступающих в аспирантуру - до 1960 г.), а с 1965 г. их прирост замедлился. Установленная закономерность, относящаяся к данному научному коллективу, отмечается и в развитии науки в целом в ӘССР и отдельно в 
Академии наук ЭССР за 1947-1970 гг. [']. Эта тенденция закономерна, так как механизм роста объема науки, который до настоящего времени описывается с помощью уравнения экспонента, под влиянием различных сдерживающих факторов постепенно переходит в новый, который можно выразить с помощью уравнения логистической кривой; это уравнение учитывает ограниченный рост [3]. Это вполне естественно, так как темпы роста числа научных работников и расходов на науку не могут долго сохраняться на прежнем высоком уровне. Вместе с тем общество нуждается в дальнейшем ускоренном развитии науки. Главным путем его обеспечения является повышение уровня подготовки научных кадров, пополнение и постоянное обновление аппаратурного базиса науки, усовершенствование организации и управления наукой, повышение эффективности исследований и ускорение использования их результатов в производстве.

\section{Квалификационная структура научных кадров}

В науке в значительно бо́льшей мере, чем в любой другой сфере человеческой деятельности, результаты зависят от квалификации и способностей сотрудников, от оптимальной организации их работы. Чтобы при наличии имеющихся кадров обеспечить наибольшую отдачу, особое внимание необходимо обратить на эффективное и целенаправленное использование каждого человека, а также на создание условий для плодотворной деятельности отдельных ученых. В большинстве случаев эта проблема решается правилыным соотношением и расстановкой работников различной квалификации в научном коллективе, рациональным функциональным разделением труда и обеспечением-ученых соответствующей техникой.

Работников научных коллективов можно разделить на три группы: 1) высококвалифицированные ученые - руководители подразделений и рабочих групп, имеющие, как правило, ученую степень; 2) научные сотрудники, не имеющие ученой степени, и аспиранты, а также инженерно-технические работники, самостоятельно выполняющие отдельные разделы изучаемых проблем под руководством ученых первой группы; 3) инженерно-технический и вопомогательный персонал.

Среди научных работников Советского Союза за период с 1950 по 1972 г. отмечается снижение удельного веса докторов с 5,3 до 2,7\%, а кандидатов с 28 до $25 \%$ [ $\left.{ }^{4}\right]$. В Эстонской ССР в целом удельный вес специалистов высшей квалификации возрос с $19 \%$ в 1950 г. до $31 \%$ в 1970 г. За 1948-1970 гг. число кандидатов в республике возросло примерно на $953 \%$, а докторов - только на $233 \%$ ['].

В Институте химии, так же как в целом по республике, в конце 60-х - начале 70-х годов число ученых высшей квалификации росло несколько быстрее, чем число научных сотрудников вообще (рис. 2). Это свидетельствует о высоком уровне проводимых в институте исследований, но в то же время предупреждает об опасности «насыщения» коллектива кадрами высокой квалификации и постепенного сокращения базы и возможности отбора наиболее талантливой молодежи особенно, если учитывать ограниченный рост числа научных сотрудников.

В табл. 3 приведены соотношение научных работников без ученой степени и научных работников со степенью, соотношение инженернотехнического персонала и научных сотрудников, а также рассматривается вариант, где в число инженерно-технического персонала включены работники Опытно-технической базы АН ЭССР, обслуживающие три опытные установки, на которых под руководством и с участием сотрудников института проводятся испытания новых технологических процес- 
Соотношение научных работников без ученой степени и научных работников со степенью

\begin{tabular}{|c|c|c|c|c|c|c|c|}
\hline & 1948 & 1950 & 1955 & 1960 & 1965 & 1970 & 1975 \\
\hline $\begin{array}{l}\text { В СССР } \\
\text { В ЭССР } \\
\text { В Институте химии АН ЭССР } \\
\text { число инженерно-техниче- } \\
\text { ского персонала на од- } \\
\text { ного научного сотруд- } \\
\text { ника } \\
\text { то же + работники хими- } \\
\text { ческих установок ОТБ } \\
\text { АН }\end{array}$ & $\overline{\overline{7}}$ & $\begin{array}{l}2,0 \\
4,2 \\
2,29\end{array}$ & $\begin{array}{l}1,6 \\
2,5 \\
2,44\end{array}$ & $\begin{array}{l}2,2 \\
2,2 \\
2,80\end{array}$ & $\begin{array}{l}3,5 \\
2,3 \\
2,12\end{array}$ & $\begin{array}{l}2,7 \\
1,7 \\
1,88\end{array}$ & $\overline{\overline{1}} \overline{\overline{79}}$ \\
\hline
\end{tabular}

сов, разработанных в Институте химии. Первые две опытные установки были сооружены к 1964 г., а третья - к 1971 г.

Соотношение научных сотрудников без ученой степени и научных сотрудников со степенью в институте возрастало до 1960 г., а затем стало уменьшаться и к 1975 г. достигло минимума $(1,79)$. Это позволяет предсказать некоторое замедление прироста ученых с высшей квалификацией в Институте химии в ближайшее будущее.

Имеются данные о том, что оптимальное соотношение вспомогательного и научного персонала для институтов химии должно быть $3: 1$. При таком соотношении потери времени научных сотрудников на выполнение работ, не требующих высокой квалификации, будут наименьшими.

Для Института химии АН ЭССР это соотношение было до 1960 г. совершенно неудовлетворительным (меньше $1: 1$ ), затем оно стало постепенно улучшаться и к 1975 г. было $1,47: 1$. Если же в число вспомогательного персонала включить и сотрудников Опытно-технической базы, обслуживающих химические установки, то положение улучшится и соотношение начнет приближаться к оптимальному.

Однако нельзя быть уверенным, что увеличение числа вспомогательного персонала обязательно должно приводить к повышению эффективности научных исследований. Можно лишь предположить, что в ближайшем будущем гораздо бо́льший эффект будет достигнут за счет улучшения оснащенности научных учреждений соответствующим оборудованием, специальными приборами и материалами, упорядочения снабжения, создания специализированных фирм по наладке и ремонту научного оборудования и т. д.

В институте относительно высок процент сотрудников с высшим образов ан ием. В 1975 г. они составляли около $64 \%$ всех сотрудников института. Интересно проследить за тем, какие высшие учебные заведения являются основной базой подготовки научных кадров для Института химии. Анализировались все сотрудники с высшим образованием, работавшие в институте с 1947 по 1975 г. и проработавшие здесь по меньшей мере один год. Всего 278 человек. Из них 76 $(27,3 \%)$ проработали в Институте химии меньше 3 лет, среди последних 6 человек были кандидатами наук. До 1975 г. из рассматриваемых 278 сотрудников институт покинули по разным причинам 90 человек $(32,4 \%)$. Сразу после окончания вузов на работу в институт пришло 133 человека $(47,8 \%)$.

Из специалистов с высшим образованием 149 человек $(53,6 \%)$ окончили Таллинский политехнический институт, $70(25,2 \%)$ - Тартуский 
государственный университет, 37 (13,3\%) - различные вузы СССР; 16 человек $(5,7 \%)$ окончили вузы до 1940 г. в буржуазной Эстонии или в Советском Союзе и $6(2,2 \%)$ - педагогические институты.

Весьма любопытные результаты получены при анализе расстановки и использования в институте специалистов по специальностям, приобретенным в вузах (табл. 4). Здесь учитывается характер деятельности сотрудника за последние годы (до 10 лет) его работы в институте. Конечно, многим специалистам, особенно проработавшим в институте более 10-15 лет, пришлось один или более раз переквалифицироваться, поэтому все изменения учесть невозможно. Почти половина специалистов с высшим образованием, работавших или работающих в институте, была вынуждена изменить специальность в связи с изменением тематики исследований или же использовалась не по специальности, приобретенной в вузе.

Таблица 4

Использование специалистов с высшим образованием в Институте хнмии

\begin{tabular}{|c|c|c|c|c|c|}
\hline \multirow{2}{*}{ Специальность } & \multirow{2}{*}{$\begin{array}{l}\text { Количест- } \\
\text { во специ- } \\
\text { алистов }\end{array}$} & \multicolumn{2}{|c|}{$\begin{array}{l}\text { Из них работает } \\
\text { по специальности }\end{array}$} & \multicolumn{2}{|c|}{$\begin{array}{r}\text { Не работает по } \\
\text { специальности }\end{array}$} \\
\hline & & $\begin{array}{l}\text { количе- } \\
\text { ство }\end{array}$ & $\%$ & $\begin{array}{l}\text { количе- } \\
\text { ство }\end{array}$ & $\%$ \\
\hline Химия (в университетах) & 70 & 65 & 92,9 & 5 & 7,1 \\
\hline $\begin{array}{l}\text { Неорганическая и аналитическая хи- } \\
\text { мия и технология } \\
\text { Химическая технология топлива }\end{array}$ & $\begin{array}{l}20 \\
61\end{array}$ & $\begin{array}{r}8 \\
32\end{array}$ & $\begin{array}{l}40,0 \\
52,5\end{array}$ & $\begin{array}{l}12 \\
29\end{array}$ & $\begin{array}{l}60,0 \\
47,5\end{array}$ \\
\hline $\begin{array}{l}\text { Процессы и аппараты химнческой } \\
\text { технологии }\end{array}$ & 26 & 11 & 42,3 & 15 & 57,7 \\
\hline $\begin{array}{lll}\text { Технология } & \text { пищевых } & \text { продуктов, } \\
\text { пластмасс, удобрений, целлюлозы } \\
\text { и др. }\end{array}$ & 45 & 8 & 17,8 & 37 & 82.2 \\
\hline Педагогика (химия, естественные нау- & 6 & 一 & - & 6 & 100,0 \\
\hline $\begin{array}{l}\text { Другие (физика, математика, электро- } \\
\text { техника и т. д.) }\end{array}$ & 50 & 29 & 58,0 & 21 & 42,0 \\
\hline Всего & 278 & 153 & 55,0 & 125 & 45,0 \\
\hline
\end{tabular}

Чаще всего по специальности работают те, кто окончил университет. Это вполне понятно, так как значительная часть исследований, проводимых в институте, носит фундаментальный характер. Химики широкого профиля, которых готовят университеты (особенно ТГУ), легко и быстро осваивают в институте узкие направления и имеют достаточную теоретическую подготовку для быстрого включения в научную жизнь института.

В 50-х годах в тематике института на первом месте стояли проблемы химии и технологии горючих сланцев. Специалистов по этому направлению готовил в основном Таллинский политехнический институт. До 60 -х годов $90 \%$ технологов топлива работала в институте по специальности, а с расширением профиля работы института в 60-х годах многим из них пришлось переквалифицироваться и начать работать в области химии и технологии органических соединений, а также физической химии. Так как конечной целью большинства исследований, проводимых в институте, является разработка технологии производства тех или иных групп соединений, то знания химиков-технологов, подготовленных по различным узким специальностям, а также специалистов в области 
процессов и аппаратов химической технологии находят применение именно в стадии разработки и испытания новой технологии.

Довольно большую группу составляют специалисты нехимических профилей. Их доля среди сотрудников института все более возрастает в связи с расширением исследований по математическому моделированию процессов химической технологии, по планированию опытов с внедрением новой сложной физико-химической аппаратуры и ЭВМ. Все больше в институте требуются физики, способные работать на современных приборах физико-химического исследования, электроники, обслуживающие сложную аппаратуру, математики и программисты, а также биохимики.

Характерными чертами современной научно-технической революции являются быстрый рост и размежевание новых направлений внутри каждой отрасли науки, а также комплексность крупных научных проблем, требующих совместных усилий специалистов различных специальностей. В этом процессе происходит формирование специалистов нового типа, чей профиль не всегда укладывается в принятую классификацию наук и номенклатуру специальностей. Удовлетворять спрос на специалистов по новым направлениям путем подготовки их в вузах нельзя, так как наука гораздо более динамичная система, чем образование. Прогресс науки настолько быстрый, что научному работнику приходится периодически переквалифицироваться, осваивать новые граничные области науки. Современная наука требует от ученых все бо́льшей профессиональной мобильности и гибкости в организации научных исследований. Вместе с тем более быстрыми темпами должна совершенствоваться и система образования, а планирование подготовки специалистов должно идти в ногу с возрастающими требованиями развивающейся науки.

Основной формой подготовки специ алистов высшей к в а л и фи к а ц и в Академии наук является аспирантура. При Академии наук ЭССР аспирантура создана в 1947 г.

В стационарной аспирантуре при Институте химии за рассматриваемый период обучалось 70 человек, 8 из которых прервали учебу по разным причинам. Кандидатские диссертации из них защитили 38 человек $(54,3 \%)$. В научных учреждениях продолжают работать $57(81,4 \%)$ бывших аспирантов, 20 из которых к 1 января 1976 г. еще не защитили диссертации.

В заочной аспирантуре обучался 31 человек, 8 из них прервали обучение. Диссертации защитили 10 человек $(29,0 \%)$. В научных учреждениях работает 20 бывших аспирантов-заочников $(64,5 \%), 12$ из них еще не защитили диссертации.

Из 71 кандидатской диссертации, завершенной сотрудниками Института химии за $1947-1975$ гг., $50(70,4 \%)$ подготовлены в рамках аспирантуры (из них 2 человека проходили аспирантуру при других институтах, а работу завершили в Институте химии).

Как видно по рис. 3, с 1961 г. темп прироста числа поступающих в аспирантуру стал постепенно замедляться.

Если рассматривать эффективность аспирантуры по количеству защищенных диссертаций и по времени, требуемому для завершения работы, то можно увидеть, что в среднем (рассматривая вместе очную и заочную аспирантуру) лишь $47,5 \%$ всех аспирантов защитили диссертации. Следует также отметить, что $35,7 \%$ диссертантов завершили работу в срок аспирантуры, $10,4 \%$ - через год после окончания аспирантуры, $14,6 \%$ - через 2 года, $18,7 \%$ - через 3 года и $20,9 \%$ - через 4 года и больше, 
Таблица 5

Распределение аспирантов Института химии до 1975 г. по специальностям

\begin{tabular}{|c|c|c|c|c|c|c|c|}
\hline \multirow[b]{2}{*}{ Специальность } & \multirow[b]{2}{*}{ 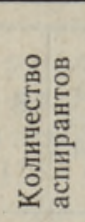 } & \multirow[b]{2}{*}{$\%$} & \multirow{2}{*}{ 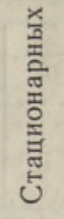 } & \multirow[b]{2}{*}{ 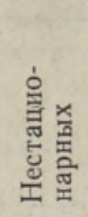 } & \multicolumn{3}{|c|}{ Диссертации защитили } \\
\hline & & & & & 部。 & 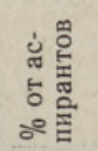 & 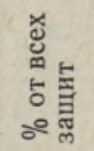 \\
\hline $\begin{array}{l}\text { Неорганнческая химия } \\
\text { Аналитическая химия } \\
\text { Органическая химия } \\
\text { Физическая хнмия } \\
\text { Хнмия высокомолекулярных }\end{array}$ & $\begin{array}{r}1 \\
1 \\
42 \\
12\end{array}$ & $\begin{array}{r}1,0 \\
1,0 \\
41,5 \\
11,9\end{array}$ & $\begin{array}{r}1 \\
1 \\
30 \\
11\end{array}$ & $\frac{-}{12}$ & $\begin{array}{r}1 \\
1 \\
19 \\
6\end{array}$ & $\begin{array}{r}100,0 \\
100,0 \\
45,2 \\
50,0\end{array}$ & $\begin{array}{r}2,1 \\
2,1 \\
39,5 \\
12,5\end{array}$ \\
\hline $\begin{array}{l}\text { соединений } \\
\text { Химия нефти и нефтехимиче- }\end{array}$ & 8 & 7,9 & 7 & 1 & 5 & 63,5 & 10,4 \\
\hline $\begin{array}{l}\text { ский синтез } \\
\text { Технология редких, радиоак- }\end{array}$ & 4 & 3,9 & 3 & 1 & 2 & 50,0 & 4,2 \\
\hline $\begin{array}{l}\text { тивных и рассеянных ве- } \\
\text { ществ } \\
\text { Технология основного органи- }\end{array}$ & 3 & 3,0 & 1 & 2 & 2 & 66,0 & 4,2 \\
\hline $\begin{array}{l}\text { ческого синтеза } \\
\text { Технология тонкого органиче- }\end{array}$ & 2 & 2,0 & 2 & - & - & - & - \\
\hline $\begin{array}{l}\text { ского синтеза } \\
\text { Химнческая технология топ- }\end{array}$ & 4 & 4,0 & 1 & 3 & 1 & 25,0 & $2,1$. \\
\hline $\begin{array}{l}\text { лива и газа } \\
\text { Процессы и аппараты хими- }\end{array}$ & 18 & 17,8 & 11 & 7 & 10 & 55,5 & 20,8 \\
\hline $\begin{array}{l}\text { ческой технологии } \\
\text { Химическое сопротивление }\end{array}$ & 2 & 2,0 & - & 2 & - & - & - \\
\hline $\begin{array}{l}\text { материалов и защита от } \\
\text { коррозин } \\
\text { Обогащение полезных иско- }\end{array}$ & 1 & 1,0 & - & 1 & - & - & - \\
\hline История науки и техники & 2 & 2,0 & 2 & - & 1 & 50,0 & $\overrightarrow{2,1}$ \\
\hline & 101 & 100,0 & 70 & 31 & 48 & & 100,0 \\
\hline
\end{tabular}

Распределение аспирантов по специальностям приведено в табл. 5. Больше всего $(41,5 \%)$ аспирантов занималось по специальностям: органическая химия, химическая технология топлива и газа, физическая химия и химия высокомолекулярных соединений, по которым наиболее высокой оказалась , и относительная результативность работы аспирантов.

Следует отметить, что из стационарных аспирантов до 1975 г. были откомандированы в другие научные учреждения Союза ССР 15 человек. Все они, за исключением одного, защитили диссертации. Очевидно, прохождение аспирантуры в новых научных коллективах мобилизует силы аспирантов, а творческая атмосфера, царящая в больших коллективах, и высококвалифицированное руководство аспирантами в институтах Академии наук СССР способствуют относительно быстрому завершению диссертационных работ.

Представляет интерес и анализ некоторых показателей, характеризующих подготовку диссертационных работ вообще сотрудниками института - как аспирантами, так й экстернами. Как уже упоминалось выше, сотрудниками института защищена 71 кандидатская диссертация. Помимо них, при институте в пернод с 1947 по 1975 г. завершено 6 докторских диссертаций (табл. 6).

При рассмотрении вопроса о времени, необходимом сотруднику для подготовки кандидатской диссертации (табл. 7), выяснилось, что в 
Количество защищенных диссертащий и прирост по сравнению с каждым предыдущим периодом в Институте химии

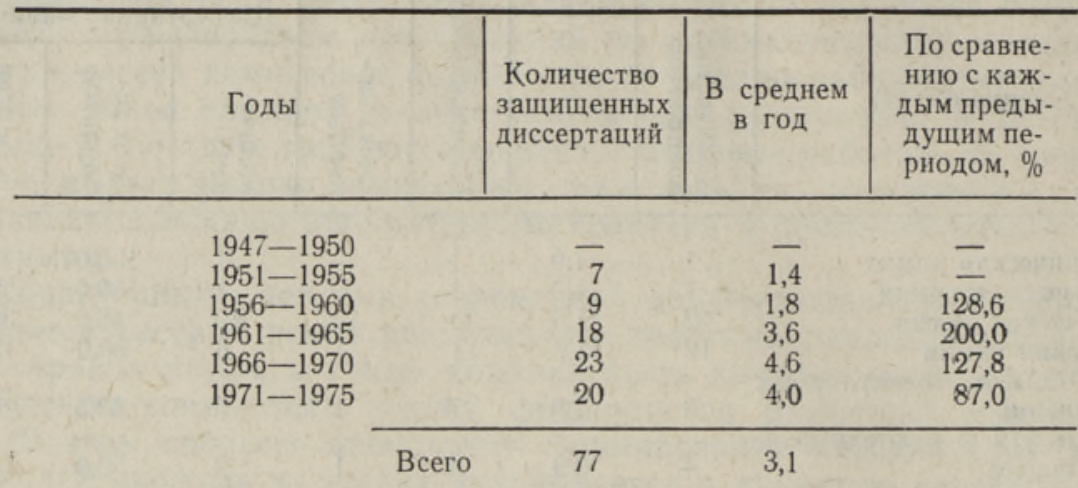

таблица 7

Срок, необходимый для подготовки кандидатской диссертации с момента поступления на работу в Институт химии (за $1947-1975$ гr.)

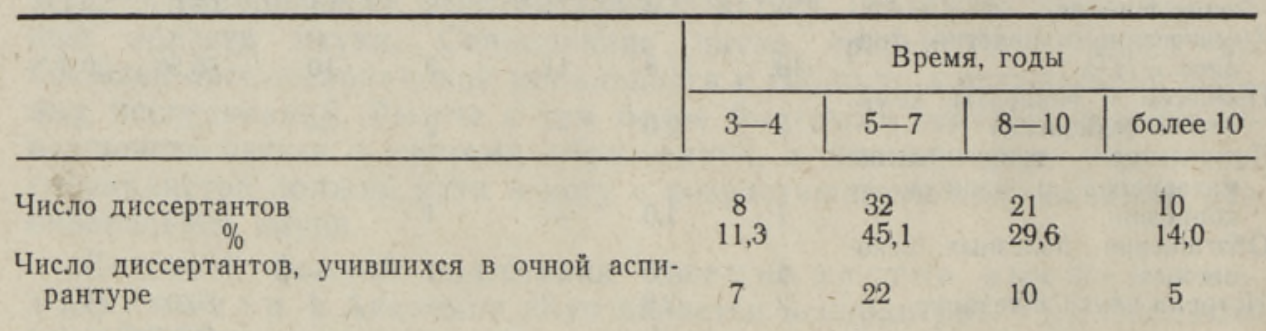

При ме ч н и е: Общее число диссертантов за рассматриваемый период 71 .

основном диссертационные работы завершаются примерно через 58 лет с момента поступления диссертанта на работу. Следует иметь в виду, что характер труда химиков-исследователей предполагает освоение или разработку методики работы на сложной аппаратуре, проведение десятков и сотен опытов и выполнение большого объема вспомогательных операций. Неблагоприятное же соотношение научного и инженерно-вспомогательного персонала почти не позволяет диссертантам (особенно аспирантам) пользоваться помощью лаборантов. Нередки к тому же случаи многократного изменения темы диссертации в связи с неосуществимостью первоначально выдвинутой задачи, получением отрицательных результатов или отсутствием соответствующей аппаратуры. В последние 10 лет средний период времени на подготовку диссертационной работы удлинился до 7-9 лет (см. табл. 8). Специального изучения и анализа требуют причины, обусловливающие это явление.

Что же касается подготовки в Институте химии докторских диссертаций, то здесь, как и в СССР и ЭССР в целом, к сожалению, дело обстоит неблагополучно.

В Институте химии за рассматриваемый период подготовлено только шесть докторских диссертаций. Период между защитой кандидатской и докторской диссертаций составляет 10, 12, 15, 18 и 25 лет. Все докторские диссертации, за исключением одной, посвящены вопросам химии и технологии горючих сланцев, т. е. обобщают результаты исследова- 
ний в области, которая в настоящее время постепенно отходит на второй план среди направлений, разрабатываемых в институте. Следует отметить, что в институте руководителями групп или секторов являются кандидаты наук, которые защитили диссертации до 1960 г. (12), и сотрудники, имеющие по $30-70$ научных публикаций $(5-6)$. Это значит, что по меньшей мере $10-15$ сотрудников имеют достаточный научный опыт для того, чтобы стать докторами наук. Однако институтский план подготовки докторских диссертаций систематически не выполняется, несмотря на то что над каждой диссертабельной темой, зафиксированной в плане, работает не один сотрудник, а целая группа.

\section{Возрастная структура научных кадров}

Возрастной состав научных кадров является существенным аспектом их общей структуры. Опыт мировой науки свидетельствует о том, что большинство наиболее значительных научных результатов получено учеными в возрасте от 26 до 40 лет.

Для анализа возрастной структуры научных кадров Института химии мы брали всех сотрудников, имеющих высшее образование, поскольку задачи у научных сотрудников без ученой степени и инженеров с высшим образованием в сущности одинаковые, а распределение обязанностей при выполнении работы больше зависит от специальности и наклонностей сотрудника, нежели от занимаемой им должности. Отдельно было рассмотрено изменение возрастной структуры сотрудников, имеющих ученые степени.

При сравнении возрастной структуры сотрудников с высшим образованием в 1950, 1960, 1970 и 1975 гг. (рис. 4) выясняется, что наряду с увеличением общей численности сотрудников института до 1970 г. имело место и значительное омоложение их состава. К 1970 г. сотрудники моложе 30 лет составляли почти половину всего творческого коллектива института, а сотрудники в возрасте до 40 лет, т. е. в возрасте наибольшей творческой активности, - почти $75 \%$. Однако к 1975 г. научный коллектив института несколько постарел. Доля до 30 -летних уменьшилась до $30 \%$, до 40 -летних - до $63 \%$, а удельный вес $41-50$-летних возрос до $24 \%$. Это вполне закономерно, так как основная часть молодежи, поступившей на работу в институт в 60-х годах, работает здесь и сейчас, а темп прироста научных сотрудников после 1965 г. замедлился.

Что же касается сотрудников, имеющих ученые степени, то здесь наблюдается противоположная картина. 1950 г. можно не рассматривать, поскольку свонх кадров с учеными степенями институт еще не успел подготовить. В 1960 г. более $72 \%$ высококвалифицированных ученых института были моложе 40 лет. К 1970 г. сотрудников моложе 30 лет, имеющих ученые степени, не осталось, сотрудники моложе 40 лет составляли лишь около $35 \%$ ученых, имеющих степень, а основное количество $(45 \%)$ ученых со степенью было в возрасте $41-50$ лет. В 1975 г. 


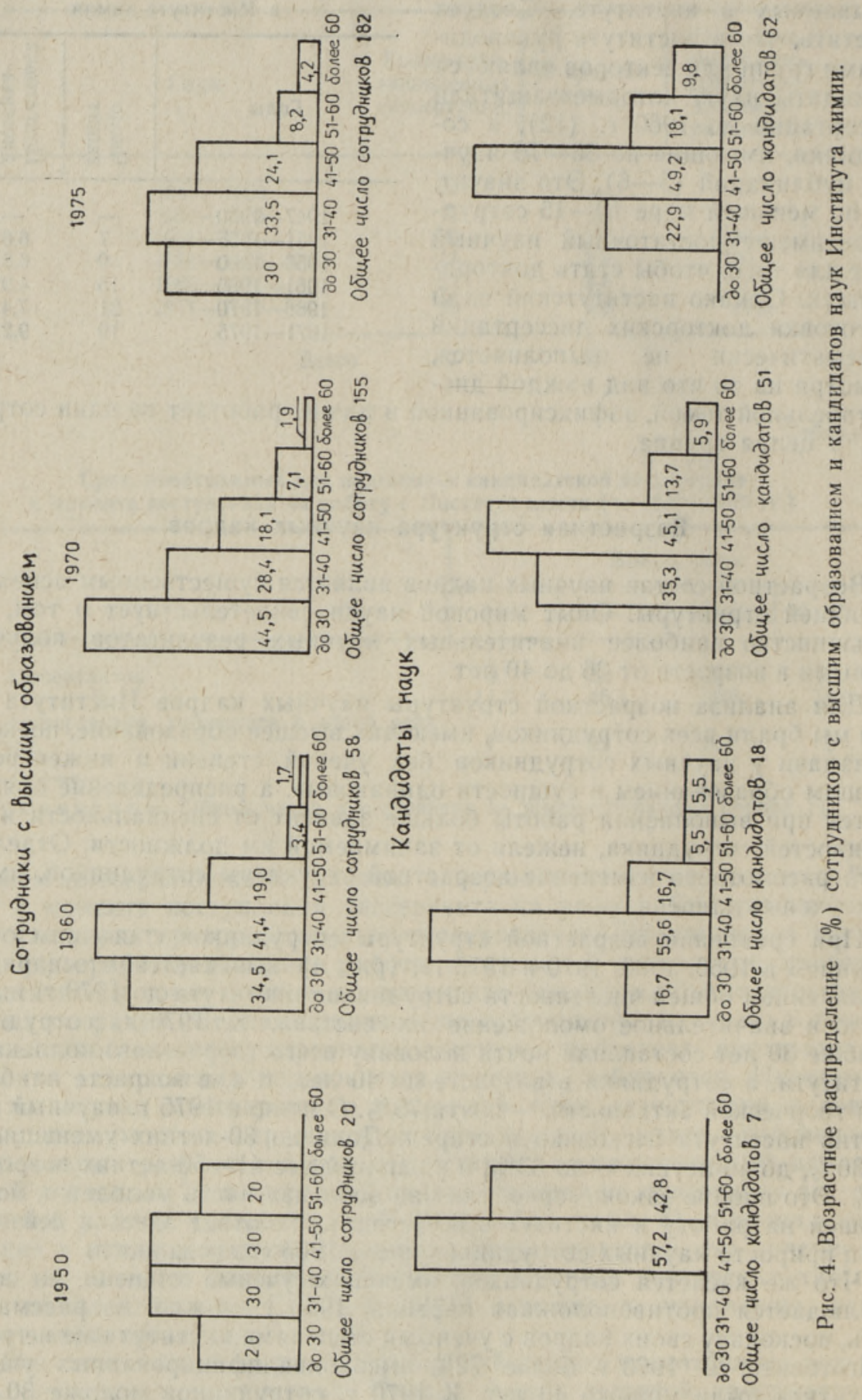


среди сотрудников с учеными степенями также не было ученых моложе 30 лет. В возрасте до 40 лет с учеными степенями было лишь $23 \%$, в возрасте $41-50$ лет - $49 \%$, а в возрасте старше 50 лет - $28 \%$, т. е. произошло значительное старение высококвалифицированных кадров.

В этом нет ничего удивительного, так как ученые, подготовившие свои диссертации при институте, как правило, остались в нем и работать (Институт химии покинуло $16 \%$ всех кандидатов наук, подготовивших при нем свои диссертации). В то же время первые кандидатские диссертации были завершены в институте более чем 20 лет назад, т. е. все кандидаты, начавшие здесь свою творческую деятельность, еще продолжают работать, а прирост кандидатов за счет молодых ученых в данном относительно маленьком научном коллективе не может превысить старение ученых со степенями. Единственным фактором, на который необходимо обратить серьезное внимание, является фактическое отсутствие кандидатов моложе 30 лет.

Если проанализировать возрастное распределение всех диссертантов института за весь период, то можно увидеть, что 15,6\% из них защитили диссертации в возрасте до 30 лет, $40,8 \%$ - в возрасте $31-35$ лет, $35,3 \%$ - в возрасте $36-40$ лет, $6,6 \%$ - в возрасте $41-50$ лет и $1,7 \%$ в возрасте старше 50 лет. Это означает, что до настоящего времени больше половины высококвалифицированных сотрудников института получили ученую степень в возрасте, соответствующем подъему их творческой активности.

Период между защитой кандидатской и докторской диссертаций велик. В СССР он составляет в среднем 12 лет ['], в Институте химии 15,8 года. Средний возраст докторов наук в институте составляет 48,1 года и совпадает с показателем для Советского Союза (49 лет в начале 60 -х годов). Тенденция к старению ведущих научных кадров отмечается и за рубежом. Это отчасти объясняется изменением специфики научного процесса, усложнением информационной обстановки и методики исследований, а также возрастанием коллективности в работе и появлением необходимости в научном и организационном руководстве большими коллективами.

\section{ЛИТЕРАТУРА}

1. Martinson, K., Teadlane ja teaduslik publikatsioon Eesti NSV-s. TIn., 1973.

2. Годовые отчеты Института химии, списки сотрудников. Центральный научный архив AH ЭСCP, ф. 14 , оп. $2,4$.

3. П р а й с Д., Неизбежность упадка. Литературная газета, от 25 августа 1971 г.

4. К ли м н ю к В. Н., Управление развитием и использованием научного потенциала. Киев, 1974 , с. 34.

5. Народное хозяйство Эстонской ССР в 1974 году. Статистический ежегодник. Таллин, 1976 , с. $333-335$. 